\title{
The association between neighborhood stressors and asthma prevalence of school children in Winnipeg
}

\author{
Tyler P Pittman ${ }^{1 *}$, Anita L Kozyrskyj ${ }^{1}$, Allan B Becker ${ }^{2}$ \\ From Canadian Society of Allergy and Clinical Immunology Annual Scientific Meeting 2010 \\ Victoria, Canada. 3-6 November 2010
}

\section{Background}

Neighborhood stressors have an incubating effect for a variety of diagnoses on maternal and child health [1]. It is of interest to determine if the Odds of asthma prevalence is greater amongst children of chronic stress neighborhoods, after adjusting for covariates such as family history of asthma and socioeconomic status. Winnipeg, Manitoba is used as study location with the urban component of children resident of birth home (698 responses) extracted from the Study of Asthma, Genes and the Environment (SAGE) Survey administered in 2002-2003 to a birth cohort from 1995 [2].

\section{Results}

The Odds Ratio of asthma amongst children residing in census tracts for the fourth and fifth quintiles of proportion males age $15+$ and unemployed was $77.8 \%$ (OR: 0.222 , p-value: 0.001 ) and $63.9 \%$ (OR: $0.361, \mathrm{p}$-value: $0.020)$ lower, respectively, than asthma prevalence in the lowest proportion of males age 15+ and unemployed quintile. Additionally, Odds of asthma for residents of the fourth highest quintile census tracts of labor force participation age $15+$ was over two and half times (OR: 2.645, p-value: 0.011 ) greater than that of children residing in the lowest quintile. From the 2001 Winnipeg Police Service Crime Data, children of profile Downtown East with the highest theft over $\$ 5,000$ crime rate had 2.44 (OR: 1.088 per unit change, p-value: 0.039) greater Odds of asthma than those in profile River Heights East with the lowest crime rate.

\section{Conclusions}

Children from neighborhoods assigned low SES scores by compositional stressors obtained from the 1996 Canada Census were found to have a decreased Odds of parent report of asthma. However, children resident of neighborhood profiles with high contextual stressor crime rates obtained from the Winnipeg Police Service Crime Data, 2001 had increased Odds of asthma. The effect of neighborhood was attributable to small proportion of variance in asthma report.

\section{Author details}

${ }^{1}$ Department of Pediatrics, University of Alberta, Edmonton, Alberta, Canada. ${ }^{2}$ Department of Pediatrics \& Child Health, University of Manitoba, Winnipeg, Manitoba, Canada.

Published: 4 November 2010

\section{References}

1. Matheson Fl, Moineddin R, Dunn JR, Creatore MI, Gozdyra P, Glazier RH: Urban neighborhoods, chronic stress, gender and depression. Soc. Sci. Med. 2006, 63(10):2604-2616.

2. Kozyrskyj AL, Hayglass KT, Sandford AJ, Parq PD, Chan-Yeung M, Becker AB: A novel study design to investigate the early-life origins of asthma in children (SAGE study). Allergy 2009, 64:1185-1193.

doi:10.1186/1710-1492-6-S2-P17

Cite this article as: Pittman et al:: The association between

neighborhood stressors and asthma prevalence of school children in Winnipeg. Allergy, Asthma \& Clinical Immunology 2010 6(Suppl 2):P17. 